\title{
The Digital Divide: Some Explanations
}

\author{
Rachel Lloyd, Jock Given and Otto Hellwig
}

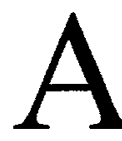

ccess to and use of the Internet and other telecommunications services are rapidly becoming an increasingly common and critical part of commerce, education and social participation. Groups with little opportunity to participate in the services providerd by new telecommunication technologies will be increasingly disadvantaged socially and economically. There is concern that differential access to modern communications services will create two separate classes in society: the 'information rich' that readily have access to new information sources such as the Internet and the 'information poor' that have limited or no access to the new services and are thus likely to be disadvantaged. The concept of a 'digital divide' is being used by bodies such as the US National Telecommunications and Information Administration (NTIA) to describe disparities in the use of the Internet and new telecommunications services across different social groups (NTIA, 1999) and 2000).

In Australia, the debate has taken a regional focus because of observed differences in metropolitan and regional rates of access to new telecommunications services. People living in non-metropolitan areas are thought to be 'digitally' disadvantaged because of the relatively high costs and poor quality of services available to them. There have been strong and consistent calls from community leaders for improved telecommunications services in regional areas. In part this should be seen as an element of the broader issue of regional diversity that has become a hot topic in Australia's policy agenda. Cuts in government, banking and teleciommunication services, coupled with low commodity prices and high unemployment rates, have prompted an outcry from those living in regional Australia albout the growing divide between the cities and the bush. The regional backlash against the Kennett government in the Victorian state election and the rise of partieis such as One Nation have focussed both state and federal governments on policies to assist regional areas. Regional members of the Coalition government have been opposed to the full privitisation of Telstra because of its perceived negative effects on services in regional areas.

Responding to these pressures, the Telecommunications Service Inquiry, headed by Tim Besley, was commiissioned by the Commonwealth Government in March 2000 to assess the adequacy of telecommunications services in Australia. The inquiry received a large proportion of its submissions from customers in rural

Rachel Lloyd is a Research Fellow and Dr Otto Hellwig is Director of Market Research and Regional Modelling at NATSEM. Jock Given is a Senior Research Fellow at the Institute for Social Research, Swinburne University of Technology and was the Director of the Communications Law Centre, UNSW and Victoria University when this research was conducted. 
and remote Australia, and many expressed concerns about the timely installation, repair and reliability of basic telephone services, the cost of mobile phone service, and the reliability, speed and cost of accessing the Internet in regional areas. The inquiry report (DCITA, 2000:7) recommended that the government

continue to provide financial and strategic assistance to ensure that those currently disadvantaged - especially in regional, rural and remote Australia - are able to take their place in an information society.

Specific recommendations suggested that government policies, regulation and support be targeted towards improving communication services in rural and remote areas. In response to the inquiry, the government committed to developing a plan of action to address the concerns of consumers living in rural and remote areas. It also committed to not selling the Commonwealth's remaining shareholding in Telstra until the plan of action had been considered and made public (Alston, 2000).

\section{Telecommunications Liberalisation, Competition and Social Policy}

The 1990s has been a period of enormous change in telecommunications policy in Australia and many other countries. Until then, governments around the world relied primarily on government ownership of monopoly post, telegraph and telephone companies to deliver social policy outcomes in telecommunications. Typically, the most important of these outcomes was the universal availability of high quality, affordable basic communications services.

The basic telecommunications service was the telephone - the ability to make and receive voice calls. The availability of other kinds of electronic and physical communications services, such as television and radio broadcasting and public libraries offering access to printed media, was also an important policy goal, but it was pursued through the establishment and funding of public broadcasters and the licensing obligations of commercial and community broadcasters, not as part of telecommunications policy.

Although there was considerable pressure for telecommunications policy change in Australia in the 1980s, and major shifts in policy in key overseas territories (including the break-up of the AT\&T monopoly in the US, the privatisation of British Telecom in the UK and unparalleled deregulation of New Zealand broadcasting and telecommunications), major policy change did not occur in Australia until late in that decade, and the most important changes have occurred in the 1990s.

The introduction of facilities-based competition into Australian telecommunications, commencing with the licensing of new fixed line and mobile carriers in the early 1990s, and the part privatisation of Telstra in two stages in the second half of the decade, have marked a decisive shift towards a greater reliance on market place disciplines to drive improved outcomes for residential and 
business consumers - faster roll-out of services, greater diversity in product offerings, lower prices and enhanced service quality.

A key reason for this greater reliance on markets in the delivery of services has been the increasing heterogeneity of consumer demand for telecommunications services. As the capabilities of new services have grown and consumer interests have diversified, the existence of a range of service providers deploying different technologies and business strategies has been seen as crucial to satisfying those increasingly complex and shifting demands.

While embarking on this fundamental change in the mechanisms of telecommunications policy, governments in Australia and elsewhere have stressed their continuing commitment to traditional social policy goals in telecommunications. Indeed, the growth of the 'information economy' and the 'knowledge society' has drawn communications policy even closer to the centre of political and economic debate. The detrimental consequences of lack of access to the basic communications tools of the age for an individual's ability to participate effectively in economic and social life has become a key political issue of our times. Further, the rapid changes in technologies and services mean that the task of ensuring equitable access to basic services is no longer the kind of once-off engineering planning mission which characterised national telecommunications strategies like the Community Telephone Plan in the 1960 s, but a dynamic ongoing challenge.

In a policy environment dominated by the sometimes frantic rhetoric of erherging opportunities - lost, grasped and ripe-for-the-taking — the task for government is to identify appropriate goals and ways in which it may be able to intervene in markets to support their achievement, without the costs of intervention outweighing the benefits. said:

In its policies for the 1996 federal election, the Liberal National Coalition

The pre-eminent role of government in the contemporary economic environment is to foster a climate of equitable opportunity, to provide for those in our community who cannot provide for themselves and to regulate where necessary the activities of the private sector in the public interest.

In office, the Coalition has introduced a number of regulatory and funding initiatives to encourage broader access to the Internet and new communications services.

\section{Current telecommunications policy measures}

Current legislation and funding programs incorporate a wide range of measures directed at ensuring equitable access to current and emerging communications services. The major interventions can be grouped under several headings (Given, 2000): 
Services

- Statutory universal service arrangements requiring standard telephone services, digital deta services, payphones and 'prescribed carriage services', together with certain ancillary equipment and services, to be made 'reasonably accessible to all Australians regardless of where they reside or carry on business'.

- Statutory requirements for standard telephone service customers to have access to emergency call services, operator services and directory assistance.

- Statutory requirements ensuring the availability of certain equipment to enable people with disabilities to make effective use of basic communications services, including teletypewriters and a national text/voice translation service, and certain adaptations to standard handsets.

- Funding programs, the most significant of which is the Regional Telecommunications Infrastructure Fund. This fund, announced in 1996 and expanded since then, aims to 'assist the economic and social development of regional, rural and remote Australia by funding projects which (i) enhance telecommunications infrastructure and services in those areas; (ii) increase access to, and promote use of, services available through telecommunications networks; and (iii) reduce disparities in access to such services and facilities'. Funding under the program has been allocated across states in direct proportion to the percentage of each state's population which lives outside the state's capital city.

\section{Service delivery}

- Quality of service: a 'customer service guarantee' requires payments by service providers to residential and small business customers where certain performance standards, relating to service connection and fault rectification times and the keeping of appointments, are not met. The Minister and the Australian Communications Authority have powers to direct Telstra and service providers subject to the customer service guarantee respectively, requiring them to take certain actions to address quality of service issues.

- Billing: statutory requirement for itemisation of long distance call costs on customer bills.

- Privacy: service providers can be guilty of offences where they disclose certain information about the contents of communications, services supplied or personal information of customers.

\section{Prices}

- Untimed local calls: service providers offering standard telephone services for local calls must offer all their customers the option of untimed local voice calls, and their residential and charitable customers the option of untimed data calls. 
- Price caps: the Minister has established price contol arrangements which require, amongst other things, real reductions in the pices of certain services and groups of services supplied by Telstra. This includes requirements aimed at ensuring the reductions in local call prices in metropolitan areas are passed on to consumers in non-metropolitan areas.

The most important goal of these interventions has been to ensure reasonably similar levels of service, quality of service and price for customers in regional, rural and remote Australia to those available to customers in metropolitan Australia.

\section{Researching Barriers to Use of New Communicaticns Services}

In recent years, a large number of studies around the world have explored the characteristics of groups with different levels of access to and use of telecommunications services (see for example, NTIA 2000 and 1999, OFTEL, 2000). This work has acquired particular urgency in relation to the Internet, given perceptions of the detrimental social and economic effects of lack of access to this important new tool for communicating, gaining access to information and conducting financial transactions.

The most recent studies by the US National Telecommunications and Information Administration (NTIA 2000 and 1999) found that there has been soaring growth in access to computers and the Intemet for people in all demographic groups and locations (51.0 per cent of US households had computers and 41.5 per cent had Internet access in August 2000), but there are still major disparities in use across different groups. In particular:

- high income earners make more use of the Internet than low income earners;

- Whites and people from Asian/Pacific backgrounds use the Internet more than Blacks and Hispanics;

- people with higher educational qualifications use the Internet more than people with lower qualifications; and

- married couples with children under 18 use the Internet more than any other household type.

NTIA's findings broadly confirm trends pointed out in an earlier study by the Benton Foundation (1998). That study also suggested a range of barriers to closing the gap between low-income and high-income populations in telecommunications use and participation, including:

- reluctance by the majority of the population to publicly fund access for people on lower incomes;

- ambivalence towards technology from people on low incomes;

- lack of political clout of low-income and minority communities; and 
- the fact that minority and poor students; had significantly less access to computers in their classes than more affluentt children.

Another US study (Sax, et a:, 1998) found 80 per cent of private college freshman using email regularly, while only 41 per cent of students attending Black public colleges did so.

A study commissioned by the British telecommunications regulator, OFTEL, on take-up of the Internet in the UK (cited in OFTEL 2000) found that 18 per cent of consumers claimed to have Internet access at home, still predominant amongst the higher social grades, younger age groups, and larger households with children. Older consumers over 55 years and the DE (lower) social grades are considerably less likely to use the Internet at home or work (though OFTEL argues that this is slowly changing).

As highlighted above, previous debate on the barriers to the take-up of technology in Australia has focussed on supply side issues, such as the quality and cost of supply in rural and remote Australia. While supply side issues are real and efforts must be made to improve access to regional areas, other factors will also need to be considered and addressed in policy development. As indicated by overseas studies, socio-demographic factors may also influence access to new communications services. For example, it may well be the case that a large proportion of Australians may be unable to participate in the knowledge economy, not because of where they live, but because of their economic or social circumstances.

The influence of socio-demographic factors on the take-up of new communications services was examined by a recent study conducted by the National Centre for Economic and Social Modelling (NATSEM) at the University of Canberra (Hellwig and Lloyd, 2000). The study focused on demand side issues and used a wide range of survey data on the use of new technologies in Australia to explore the social and economic characteristics of Australians with different levels of access to and usage of communication services. The principal aim of the study was to contribute to a better understanding of the reasons for different levels of access and use, and thus to inform debate on, and consideration of, the kinds of industry and government strategies that might be most effective in encouraging broader take-up of services. The major findings of that study are summarised below.

\section{Internet Access by Different Social Groups}

Data from the Household Use of Technology Surveys conducted by the Australian Bureau of Statistics (ABS) and KPMG Household Survey were used to analyse the characteristics of users of new technology. The main findings of this analysis follow.

In March 2000,64 per cent of adults had access to a computer at home and 37 per cent of adults had access to the Internet at home. Between 1999 and 2000 there was a considerable increase in the proportion of adults with Internet access at 
home (from 25 per cent to 37 per cent) and a smaller increase in PC ownership (from 53 to 64 per cent).

Access varied most across different income groups, with 70 per cent of the top income group (more than $\$ 844,000$ ) having access in March 2000, compared with 22 per cent of the bottom imcome group (less than $\$ 19,000$ ). Details are provided in Figure 1. The take-up rate for high-income households is 3.2 times that in low-income households. Internet take-up was found to increase strongly for household incomes greater than $\$ 35,000$. It was further found that the difference in the proportion of high and low income households with Internet access at home has decreased considerably between 1999 and early 2000. In other words, the income distribution has become more even as the rate of access for those with high incomes reaches saturation point and the rate for those with low incomes continues to increase.

\section{Figure 1: Proportion of Adults with Internet Access at Home by Income Level, 1998 to 2000}

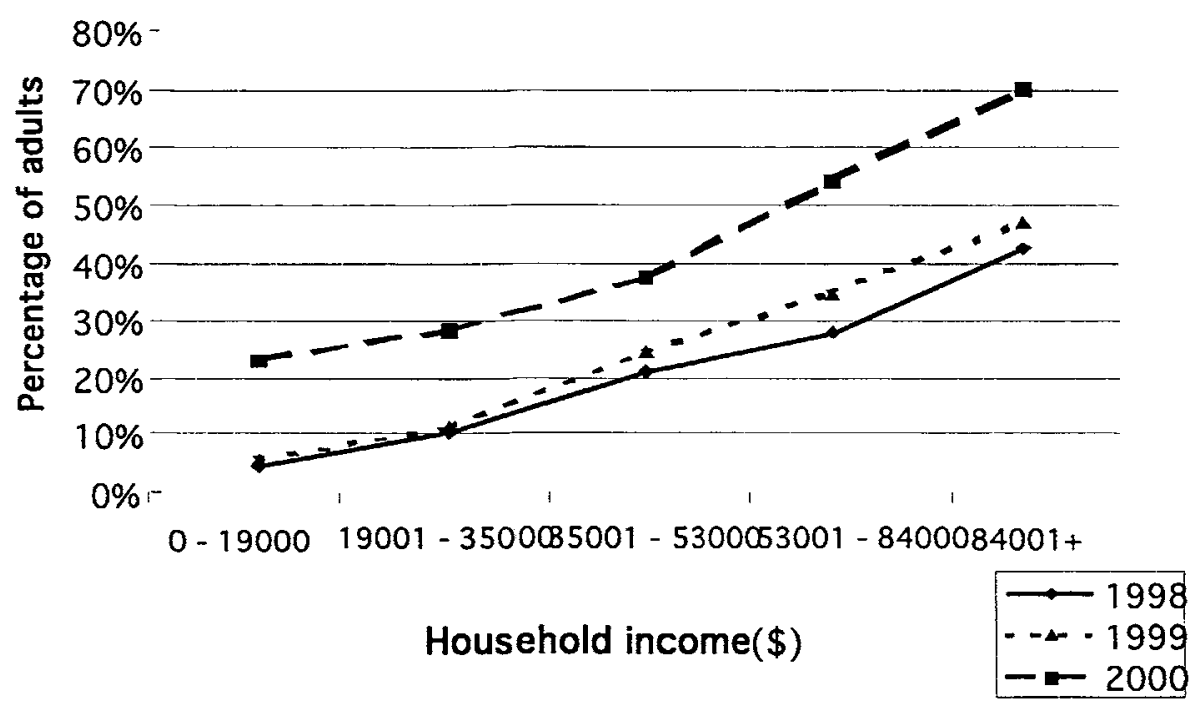

Data source: Unpublished data from ABS Household Use of Information Technology Surveys (1998 and 1999) and KPMG Household Survey (2000)

Educational qualification also had a strong influence on Internet access at home. The proportion of adults with Internet access increases with level of education. In 2000, 64 per cent of those with a Bachelor degree (or higher) had access to the Internet at home, but just 28 per cent of those with a secondary education had access. However, it appears that the low education groups have had 
higher growth rates in recent times. This is consistent with the picture of the diminishing impacts of income, as detailed above.

The third greatest variation in access was age with people younger than 55 twice as likely to have home Internet access than those aged 55 and over. For all age groups, Internet access increased from 1998 to 1999, but the growth was strongest for middle-aged and older Australians, causing the age distribution to become more even (Figure 2). From 1998 to 1999 growth was strongest for women aged 18-24 (from 21 to 31 per cent), and men aged 35-54 (an increase of eight percentage points). The proportion of women 55 and over almost doubled from 6 per cent in 1998 to 10 per cent in 1999.

\section{Figure 2: Proportion of Adults with Internet Access at Home by Age Group, 1998 to 2000}

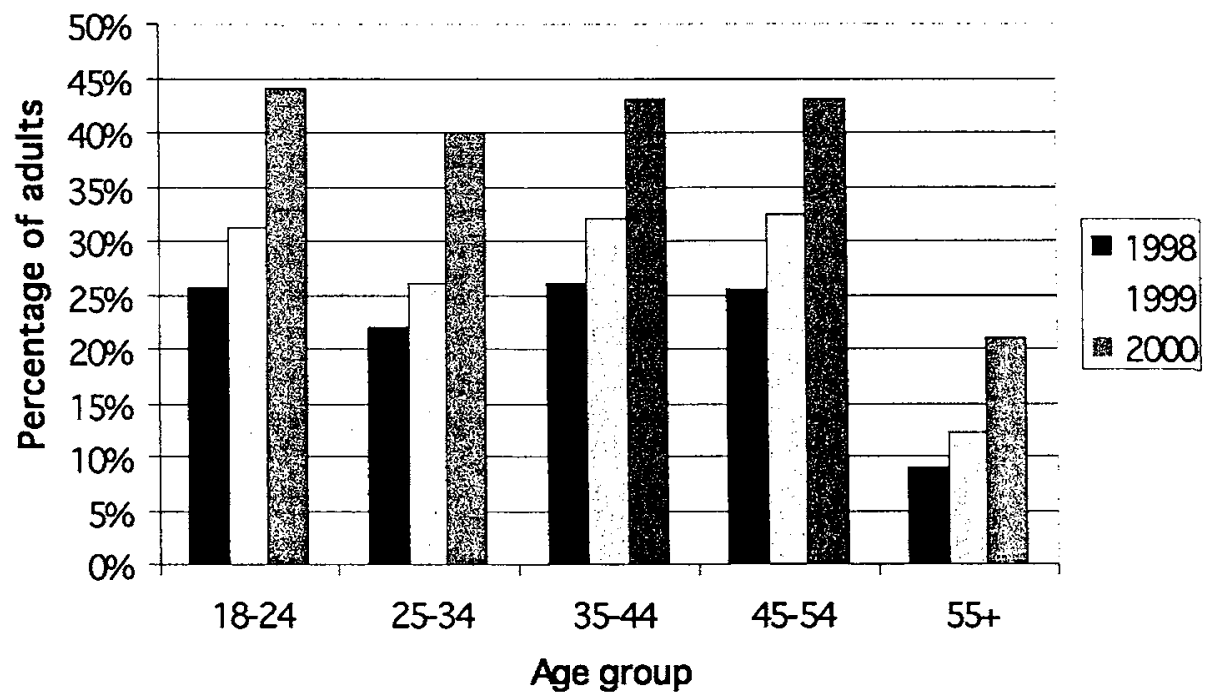

Data source: Unpublished data from ABS Household Use of Information Technology Surveys (1998 and 1999) and KPMG Household Survey (2000)

There is very little interaction between income and age as the driver for Internet access at home; the income profiles of Internet access are very similar for the various age groups. The main exceptions are high access rates for low-income people aged 18 to 24 (likely to include students) and the low incidence for persons aged 25 to 34 in the $\$ 53,000$ to $\$ 84,000$ income group. This group probably includes a greater share of single people and couples without children, who are less likely to have Internet access at home.

The presence of children was also found to increase the likelihood of a household being connected to the Internet. Households with children are more likely to have Internet access at home (Table 1). Forty per cent of adults living in 
horuseholds with children aged 15 or over have Internet access, compared with 21 per cent of adults living in households without children. The likelihood of a household having Internet access increases with the age of the children, with children aged 10 or over having the strongest effect. However, income remains a more dominant variable with high-income households with young children or no chïldren having up to three times the access rates of low-income households with a chïld aged over 10 .

\section{Table 1: Percentage of Adults With Access to the Internet at Home by Household Income and Age of the Eldest Child, 1999}

\begin{tabular}{|c|c|c|c|c|c|c|}
\hline $\begin{array}{l}\text { Household } \\
\text { Income } \\
\text { (\$) }\end{array}$ & $\begin{array}{c}0 \\
\text { to } \\
19000\end{array}$ & $\begin{array}{c}19001 \\
\text { to } \\
35000\end{array}$ & $\begin{array}{c}35001 \\
\text { to } \\
53000\end{array}$ & $\begin{array}{c}53001 \\
\text { to } \\
84000\end{array}$ & $84000+$ & ALL \\
\hline Age of eldest child & $\%$ & $\%$ & $\%$ & $\%$ & $\%$ & $\%$ \\
\hline 0 to 4 years & 8 & 9 & 24 & 35 & 50 & 27 \\
\hline 5 to 9 years & 7 & 17 & 21 & 32 & 47 & 26 \\
\hline 10 to 14 years & 16 & 17 & 32 & 40 & 55 & 35 \\
\hline 15 to 17 years & 18 & 15 & 31 & 48 & 57 & 40 \\
\hline ALL & 6 & 11 & 24 & 35 & 47 & 25 \\
\hline No children & 4 & 9 & 22 & 30 & 42 & 21 \\
\hline
\end{tabular}

Data source: Unpublished data from ABS (1999) Household Use of Information Technology Surveys.

There is considerable gap in Internet access at home between metropolitan and other areas and the gap has persisted during the past few years. Forty per cent of adults in metropolitan areas are connected at home compared with 33 per cent in rural areas and 28 per cent in other urban areas. This finding accords with other NATSEM research that found rural areas had higher incomes and higher growth in incomes in the 1990s than 'other urban areas' (Lloyd, Harding and Hellwig 2000). Contrary to common belief it is not the rural areas but the regional and rural towns that are the most economically disadvantaged regions in Australia. This is reflected in the low Internet take-up rates in other urban areas.

The difference in access by gender was found to relatively small with males being about 1.3 times more likely than females to have access to the Internet at home. The figures for Internet use, rather than access, show a wider gender gap. (ABS 1999a and 2000). 


\section{Drivers of Internet access}

A multi-variate analysis was used to determine which factors were most responsible for the differences in Internet access between groups after accounting for correlation between variables such as income; , age and education. The results are summarised in Table 2. Further detail on the methodology and results can be found in Hellwig and Lloyd (2000).

\section{Table 2: Major Drivers of Internet Access}

\begin{tabular}{|c|c|c|}
\hline Driver & Effect & Predictive Power $^{\mathrm{a}}(\%)$ \\
\hline Qualification & $\begin{array}{l}\text { Internet access increases with } \\
\text { qualification level }\end{array}$ & 20 \\
\hline Income & $\begin{array}{l}\text { Internet access increases as } \\
\text { income increases }\end{array}$ & 9 \\
\hline $\begin{array}{l}\text { Receive government } \\
\text { benefits }\end{array}$ & $\begin{array}{l}\text { Households receiving } \\
\text { government benefits are more } \\
\text { likely to have Internet acicess }\end{array}$ & 5 \\
\hline $\begin{array}{l}\text { Gender and marital } \\
\text { status }\end{array}$ & $\begin{array}{l}\text { Females are less likely to have } \\
\text { Internet access }\end{array}$ & 5 \\
\hline Age & $\begin{array}{l}\text { People over } 55 \text { are less liikely } \\
\text { to have Internet access }\end{array}$ & 4 \\
\hline Occupation & $\begin{array}{l}\text { Blue collar workers are less } \\
\text { likely to have Internet access }\end{array}$ & 4 \\
\hline State/region & No effect & 0 \\
\hline
\end{tabular}

Note: $\mathrm{a}=$ Based on predictive power of drivers net of other factors in $\%$ of total R-squared.

Data source: KPMG Survey, March 2000

The most important driver of Internet access is educational qualification (higher qualification resulting in higher access), followed by income (higher income results in higher access) and whether or not the household is in receipt of government benefits (households in receipt of benefits are more likely to have access, all else being equal).

After accounting for other drivers, region and state by themselves do not explain differences in Internet take-up rates. Observed differences in the connection rates between metropolitan and non-metropolitan areas and between some states are based on socio-demographic factors such as lower qualification levels and lower incomes of the non-metropolitan population, not on regional factors. This is a very significant finding as it clearly indicates that, while there are regional areas of disadvantage, these are a result of socio-demographic rather than geographic barriers. 


\section{Mobile Phone Usage}

The anaysis also included an examination of mobile phone usage in Australia. It was found that the socio-demongraphic drivers for mobile phone use are very different from the drivers for Intternet access. For example, while the proportion of adults with Internet access at home increases with education, tertiary education decreases the likelihood of using mobile phones (after controlling for income and other factors). Age is the most important driver of mobile phone usage. Income is only of minor relevance. The main similarities between the socio-demographic driver pitterns for Internet access and mobile phone use are that usage decreases with ageand males have higher take-up than females.

\section{Expenciture on Phone Services}

For comparitive purposes the analysis of telephony services was extended to general phone expenditures. This analysis used a modified form of the 1993-94 Househcld Expenditure Survey and found that the patterns for phone expenditures differ significantly from the take-up patterns for Internet and mobile phones.

It vas found that phone expenditures were largely driven by need and capability to pay and that there were virtually no regional or socio-demographic access or usage barriers. The strongest indicators of the level of phone expenditures were income and age. People who are overseas born or divorced/widowed/separated also spend much more than average. Qualification and occupation play only minor roles, in contrast to the newer technologies of Internet and mobile phone.

\section{Projecting Growth in Internet Access at Home}

As Intemet access has been increasing rapidly in recent years, projections were estimated of the level of access over the next three years. Survey responses to questiors about current access and the reasons for non-access were used to identify and quantify the people who are likely to connect in the short to medium term. These groups were people who:

- identified existing barriers to purchasing over the Internet which are likely to be reluced;

- currently have Internet access at work or at other sites, but not at home; or

- currently have a PC at home, but do not yet have Internet access.

Given the uncertainty that surrounds projections, several scenarios were used to establish a range within actual changes to access levels is highly likely to occur. These vere: a most likely scenario; an optimistic (maximum) scenario; and a pessimistic (minimum) scenario.

The modelling of the most likely scenario resulted in 71 per cent of adults being connected at home within the next 3 years (compared with 37 per cent in 
March 2000). Under the optimistix projection serries 81 per cent of adilts will be connected while under the pessimstic series onlly 51 per cent of aduts will be connected at home within the next 3 years.

Under the most likely scenirio almost all adults (over 95 per cent) in households with an income greatir than $\$ 65,0010$ are likely to be connected at home compared with only 50 percent of those with income less thas $\$ 24,000$. Even under the optimistic projection scenario, a. significant differentill between those with high and low incomes is ikely to remaim.

The projections also show that the differeences in Internet access levels between metropolitan and other areas are likely to grow. The difference in access rates between metropolitan and oher urban areas is projected to ris from the current 12 points to 18 percentage points (underr the most likely scemario). For rural areas the gap is expected to increase from 7 peoints to 12 percentage points.

\section{Conclusion}

The take-up of modern teleconmunications technology is lower in nonmetropolitan areas than in the cties. As shoiwn by this study, the regional differences can be explained by the different sociio-demographic characteristics of people in metropolitan and non-metropolitan areas. The most important driver of Internet access is educational qualification, followed by income. Age and qualification are the strongest drivers of mobile phone use. After accounting for other factors, region and state by themselves do not explain differences in Internet or mobile phone take-up rates.

A large proportion of Aust:alians do not participate in the snowledge economy at home, not because where they live, lbut because of their economic or social circumstances. People who have barriers to participation in the knowledge economy live in metropolitan as well as non-mietropolitan areas. For example, while 13 per cent of Australians live in rural aregions and 20 per cent live in regional towns, 63 per cent of the total population still have no access to the Internet at home. If just one-quarter of those without access cannot connect for economic reasons, the number of people affected is larger than the whole rural population.

As new technology, and particularly the Internet, becomes ircreasingly important for economic and social participation in modern society, it is vital that policy makers consider ways to improve access for the most disadvantaged. The primary social objective of key policy measures. in Australia in recent years has been to address regional inequities in the availability and affordability of telecommunications services. A major focus has been the 'supply-side' ensuring that infrastructure is available to deliver new services at increasing data speeds. The results of this study have shown that these kinds of measues will not be enough to bridge the digital divide. Improved infrastructure may improve the quality of service in regional areas but will not overcome the disparity in access rates for different social groups. Even in metropolitan areas where in rastructure is well developed, Internet take-up rates for certain social groups - bw-income 
earners, the unemployed and the elderly - have been low. A more complex social policy agenda directly targeting digitaly disadvantaged communities and families is recessary if Australia is to seriorsly address the root causes of the digital divide.

\section{References}

Australian Bureau of Statistics (1999a), Householl Use of Information Technology, Cat. no. 8146.0, Cenberra.

Australian Bureau of Statistics (1999b), Australial Standard Geographical Classification $(A S G C)$, Cat. no. 1216.0, Canberra.

Australian Bureau of Statistics (2000), Use of he Internet by Householders, Cat. no. 8147.0, May, Canberra.

Alston, R. (2000), (Senator the Hon., Ministrr for Communications, Information Technology and the Arts) 'Australia's Telecomminications Services Comparable to the Best in the World', Media Release 133/00, 12 Octoler.

Given, J. (2000), 'Consumer Issues', in Grant, A. and J Given (eds), Australian Telecommunications Regulation: The Communications Law Centre Guide, Communications Law Centre, Sydney [forthcoming.

Benton Foundation (1998), 'Losing Ground Bit by Bit: Low-Income Communities in the Information Age', New York (http://www.benton.otg/).

Department of Communications, Information Techology and the Arts (2000), Connecting Australia: Report of the Telecommunications Services Inquiry, DCITA, Canberra (http://www.telinquiry.gov.au/files/final_report.pdf).

Hellwig, O. and R. Lloyd (2000), Socio-demographic Barriers to Utilisation and Participation in Telecommunications Services and their Regional Distribution: A Quantitative Analysis, National Centre for Social and Economic Modelling, University of Canberra.

Lloyd, R., A. Harding and O. Hellwig (2000), 'Regional Divide? A Study of Incomes in Regional Australia', paper presented to 29th Annual Conference of Economists, Gold Coast, 3-6 July.

National Telecommunications and Information Administration (2000), Falling through the Net: Towards Digital Inclusion, US Department of Commerce, Washington DC (http://search.ntia.doc.gov/pdf/fttn00.pdf).

National Telecommunications and Information Administration (1999), Falling through the Net: Defining the Digital Divide, US Department of Commerce, Washington DC (http://www.ntia.doc.gov/ntiahome/fttn99/contents.html).

OFTEL (2000), Homes without a Fixed Line Phone, Office of Telecommunications, London (http://www.oftel.gov.uk/cmu/research/unph0400.htm). 
Sax, L., A. Astin, W. Korn and K. Mahoney (1998), The American Freshman: National Norms for Fall 1998, Higher Education Research Institute, UCLA Graduate School of Education and Information Studies, University of California, Los Angeles (http://www.acenet.edu/news/press_release/1999/01January/freshman_survey.html)

The authors thank the editors and Richard Percival for their valuable comments. The original research for this paper was conducted in conjunction with the Communications Law Centre and the Australian Council of Social Services and was funded by Telstra. 